\title{
REDUÇÃO DA MENORIDADE PENAL: UMA ANÁLISE A PARTIR DOS ASPECTOS CONSTITUCIONAIS
}

\author{
REDUCTION OF CRIMINAL \\ MINORITY: AN ANALYSIS FROM \\ THE CONSTITUTIONAL ISSUES
}

\author{
Ana Paula de Bittencourt ${ }^{1}$ \\ José Sérgio da Silva Cristóvam²
}

\begin{abstract}
Resumo: O presente artigotrata da possibilidade ou não de redução da menoridade penal a partir de uma análise constitucional. Para tanto, abordar-se-á os aspectos constitucionais referentes à menoridade penal, trazendo as definições e as finalidades dos princípios norteadores da aplicação da medida socioeducativa de internação, sendo estes a brevidade, a excepcionalidade e o respeito à condição peculiar de pessoa
\end{abstract}

em desenvolvimento. Por fim, verificar-se-áa exposição das opiniões de renomados juristas a respeito do art.228 da Constituição Federal de 1988, se este representa uma "cláusula pétrea" ou é passível de reforma.

Palavras-chave: Menoridade penal. Constituição federal. Inimputabilidade penal. Cláusula pétrea.

Abstract: This article deals about the

1 Especialista em Direito Aplicado pela FURB (2015), em convênio coma Esmesc. Especialista em Direito Público pela FURB (2014). Bacharel em Direito pela Unisul (2011). Residente Judicial no Tribunal de Justiça de Santa Catarina. E-mail: anabittencourt13@hotmail.com

2 Doutor em Direito Administrativo pela UFSC (2014), com estágio de Doutoramento Sanduíche no Instituto Superior de Ciências Sociais e Políticas (ISCSP) da Universidade de Lisboa (Portugal). Mestre em Direito Constitucional pela UFSC (2005). Especialista em Direito Administrativo pelo Cesusc (2003). Professor de Direito Administrativo nos Cursos de Graduação e Pós-Graduação em Direito do Cesusc. Professor de Direito Administrativo na Esmesc, na ESA-OAB/SC e na ENA/Brasil, em convênio com a ÉcoleNationale d'Administration (I'ENA/França), bem como em Cursos de PósGraduação em Direito da Unidavi, Unoesc, Unisul, UnC e Estácio de Sá. Membro fundador e Presidente do Instituto Catarinense de Direito Público (ICDP). Membro fundador do Instituto de Direito Administrativo de Santa Catarina (IDASC) e da Academia Catarinense de Direito Eleitoral (ACADE). Membro efetivo do Instituto dos Advogados de Santa Catarina (IASC). Conselheiro Estadual da OAB/SC (triênio 20162018).Presidente da Comissão de Acesso à Justiça da OAB/SC. Membro das Comissões de Direito Constitucional e da Moralidade Pública da OAB/SC.Advogado militante na seara do Direito Público. E-mail: jscristovam@gmail.com 
possibility or not to reduce the Criminal Minority from a constitutional analysis. For this, will be analyzed the constitutional aspects relating to criminal minority, bringing the definitions and purposes the guiding principles the implementation of socio-educational hospitalization as being these brevity exceptionality and respect to the peculiar conditions of the develo- ping person. Finally it will be checked to display the opinions of renowned jurists about the art. 228 of the Federal Constitution of 1988, if this represents an "entrenchment clause" or is likely to reform.

Keywords: Criminal minority. Federal constitution. Criminal unaccountability. Eternity clause.

\section{INTRODUÇÃO}

A menoridade penal é um assunto discutido com frequência nos últimos anos, inclusive por conta do aumento da repercussão sobre crimes que envolvem menores. O presente artigo pretende avaliar a possibilidade jurídica de redução da menoridade penal, isso porque o Estatuto da Criança e do Adolescente (ECA) possui processamento próprio para proteger, prevenir e ressocializar os menores infratores em absoluta consonância com os ditames da Constituição Federal.

O método de abordagem utilizado é o dedutivo, sendo que a pesquisa parte de proposições gerais, como os princípios orientadores da aplicação de qualquer medida privativa de liberdade de adolescentes e sua obediência, chegando aos argumentos específicos sobre a análise da possibilidade ou não da redução da menoridade penal, a partir dos aspectos estabelecidos na Constituição da República de 1988 .O estudo se apresenta a partir da pesquisa bibliográfica, por meio de citações doutrinárias, legislações específicas e artigos científicos.

O estudo recupera a análise de autores consagrados, tanto na área do Direito Constitucional, quanto do Direito da Criança e do Adolescente, dentre eles destacam-se Guilherme de Souza Nucci, Valter KenjiIshida e Pedro Lenza, aqui citados como fontes doutrinárias que colaboraram na redação do texto, a demonstrar a profundidade do debate sobre o tema. 
Inicialmente, são analisados os aspectos constitucionais referentes à menoridade penal, trazendo definições e finalidades dos princípios norteadores da aplicação da medida socioeducativa de internação, sendo estes a brevidade, a excepcionalidade e o respeito à condição peculiar de pessoa em desenvolvimento. Por fim, seguem as opiniões doutrinárias a respeito do art.228 da Constituição Federal de 1988, em especial sobre o debate se tal norma representa ou não exemplo de "cláusula pétrea".

\section{PRINCÍPIOS CONTITUCIONAIS DE BREVI- DADE, EXCEPCIONALIDADE E RESPEITO À CONDIÇÃO PECULIAR DE PESSOA EM DE- SENVOLVIMENTO, QUANDO DA APLICAÇÃO DE QUALQUER MEDIDA PRIVATIVA DA LI- BERDADE E SUA OBEDIÊNCIA}

As medidas socioeducativas que importam em privação de liberdade norteiam-se pelos princípios da brevidade e excepcionalidade consagrados no art. 121 do Estatuto da Criança edo Adolescente, respeitada a peculiar condição de pessoa em desenvolvimento.

Esses princípios decorrem de expressa disposição constitucional, que os contempla no inciso V do $\S 3^{\circ}$ do art. 227: "obediência aos princípios de brevidade, excepcionalidade e respeito à condição peculiar de pessoa em desenvolvimento, quando da aplicação de qualquer medida privativa da liberdade". (BRASIL, 1990).

Sobre os princípios que regem a medida socioeducativa de internação, comenta Ishida (2011, p. 263):

O Estatuto da Criança e do Adolescente, visando garantir os direitos do adolescente, contudo, condicionou-a a três princípios mestres: (1) o da brevidade, no sentido de que a medida deve perdurar tão somente para a necessidade de 
readaptação do adolescente; (2) o da excepcionalidade, no sentido de que deve ser a última medida a ser aplicada pelo Juiz quando da ineficácia de outros de outros; e (3) o do respeito à condição peculiar de pessoa em desenvolvimento, visando manter condições gerais para o desenvolvimento do adolescente, por exemplo, garantindo seu ensino e profissionalização. Em obediência à brevidade, estipula a lei menorista o prazo máximo de 3 (três) anos $\left(\S 3^{\circ}\right)$ e a liberação compulsória aos 21 (vinte e um) anos $\left(\S 5^{\circ}\right)$.

$\mathrm{Na}$ mesma linha, sobre os princípios constitucionais que regem a medida de internação, afirma Antônio Carlos Gomes da Costa (1992 apud SARAIVA, 2006, p.375):

Três são os princípios que condicionam a aplicação da medida privativa de liberdade: o princípio da brevidade, enquanto princípio cronológico; o princípio da excepcionalidade, enquanto limite lógico no processo decisório acerca de sua aplicação; e o princípio do respeito à condição peculiar de pessoa em desenvolvimento, enquanto limite ontológico, a ser considerado na decisão e na implementação da medida.

A propósito do princípio da brevidade, João Batista Costa Saraiva (2006, p. 170) sustenta que

repousa na própria condição peculiar de pessoa em desenvolvimento, levando em conta a capacidade de modificabilidade do adolescente nessa fase crucial de sua vida, onde o tempo do adolescer tem um valor distinto do tempo da vida adulta.

Braz (2001) explica que o princípio da brevidade encontra fundamento no art. $121, \S 3^{\circ}$, do Estatuto da Criança e do Adolescente, que dispõe não existir penas perpétuas, pois a medida extrema de internação não deverá exceder a três anos.Brevidade, assim como temporariedade, são determinações expressas de norma principiológica da Constituição Federal, art.227, §3º, repetidas na legislação infraconstitucional - art. 121 do Estatuto da Criança e do Adolescente.

A internação precisa ser breve. Isso quer dizer que deve al- 
cançar o menor período possível da vida do adolescente, o qual está em processo de formação e tem no direito fundamental à liberdade um dos mais relevantes fatores para a construção do caráter. A vida social, os direitos de expressão, a diversão e participação da vida política são exemplos da importância do gozo da sua liberdade, em um momento singular da sua existência (MORAIS; RAMOS, 2013, p.1.015).

Do princípio da brevidade, decorre o mandamento constitucional no sentido de estabelecer que a privação de liberdade deva permanecer pelo menor tempo possível, somente devendo manter-se até um limite máximo de três anos e com revisões periódicas ao menos a cada seis meses, até um juízo de que o adolescente está apto ao convívio social (SARAIVA, 2006, p. 171).

É evidente que a privação de liberdade traz em si um dano, devido à "contaminação" inevitavelmente presente em qualquer espaço de internação coletiva. Portanto, o menor tempo possível de privação de liberdade se constitui em garantia constitucional, até mesmo como mecanismo capaz de combater esta inevitável contaminação com outras experiências negativas (SARAIVA, 2006, p. 170).

Quanto ao princípio da excepcionalidade, na visão de Mirele Alves Braz (2001), subsumido no art. 122, $\S 2^{\circ}$, do Estatuto da Criança e do Adolescente, a privação de liberdade, neste contexto, surge como ultima ratio, após outras formas de advertência e repreensão, de conformidade à gravidade do ato infracional, não como um fim em si mesma, mas como um meio de proteger e possibilitar ao adolescente atividades educacionais que lhe forneçam novos parâmetros de convívio social. Havendo possibilidade de ser imposta medida menos onerosa ao direito de liberdade do adolescente, será esta imposta em detrimento da internação. Para tanto, dever-se-á levar em consideração as condições particulares do adolescente e a natureza do ato infracional. 
Nesse sentido, Saraiva (2006, p. 171) ressalta que o princípio da excepcionalidade se sustenta na ideia de que a privação de liberdade não constitui na melhor opção para a construção de uma efetiva ação socioeducativa somente acionável se, enquanto mecanismo de defesa social, outra opção se apresentar insuficiente.

A excepcionalidade é consequência do caráter aflitivo das medidas restritivas de liberdade, e guarda íntima relação com a necessária delimitação do poder do Estado de impingir aos indivíduos cerceamento do exercício dos seus direitos (MORAIS; RAMOS, 2013, p. 1016).

Destarte, os princípios da brevidade e da excepcionalidade operam harmonicamente entre si, visando a obstar a opção pela privação de liberdade, reservada apenas para as situações em que, do ponto de vista do interesse da sociedade e das características pessoais do adolescente, a alternativa não se faz adequada (SARAIVA, 2006, p. 172).

A propósito do princípio do respeito à condição peculiar de pessoa em desenvolvimento, Morais e Ramos (2013, p. 1016) afirmam que a medida de internação precisa respeitar a condição peculiar do adolescente como pessoa em desenvolvimento. Este princípio traz uma ótica multidisciplinar sobre o comportamento do adolescente, realçando as suas especificidades em relação ao adulto e impondo sejam levadas em conta, por todos os operadores do sistema, suas circunstanciais condições psíquicas, físicas e emocionais.

Certamente a maturidade é alcançada quando da verdadeira correspondência entre a reunião do desenvolvimento pessoal pela assunção consciente e ideológica dos valores humanos e um comportamento humanitário. Contudo, para que isso aconteça, é necessário a pessoa ser capaz de uma escolha livre e responsável (RAMIDOFF, 2008, p. 28). 
Para Braz (2001), o princípio do respeito à condição peculiar de pessoa em desenvolvimento, ínsita em inúmeros dispositivos legais como, por exemplo, o rol do art.124 do Estatuto da Criança e do Adolescente. Ele relaciona-se aos direitos e garantias fundamentais expressos na Constituição Federal e no Estatuto da Criança e do Adolescente, no sentido de zelar pela integridade física e mental dos internos, reavaliação da medida a cada seis meses, cumprimento em estabelecimento próprio.

Identificar o adolescente como sujeito de suas ações, como sujeito de direitos, e, em consequência, titular de direitos e obrigações, nem sempre acontece de forma perfeitamente compreensível por todos. Há mitos e preconceitos impedindo essa compreensão. Além disso, há um equivocado entendimento da ordem legal, resultando na crise de interpretação do Estatuto da Criança e do Adolescente (SARAIVA, 2006, p.37).

A partir de Freud, Lacan e Winnicott, em uma incursão psicanalítica sobre o tema, Sônia Carneiro Leão oferece outras reflexões sobre a adolescência, destacando o imaginário adulto frente à adolescência, uma época em quetudo é permitido e nada seria cobrado, segundo este ideal adulto da adolescência (SARAIVA, 2006, p.37).

Sobre o desenvolvimento humano, João Batista Costa Saraiva cita Sônia Leão:

Sensação de plenitude o adolescente sente, realmente. O adulto o inveja, invariavelmente. Por causa dessa plenitude o adolescente vê o mundo com as cores mais intensas. $\mathrm{O}$ mundo adulto já ficou um tanto desbotado. O jovem acha que pode tudo. Há bem pouco tempo eram crianças submetidas aos padrões éticos de suas famílias, reproduzindo fielmente os desejos do meio em que viviam. Agora têm estilo próprio. Vestem-se de modo peculiar. Cantam músicas que lhe são destinadas especialmente, e já têm pontos de vistas próprios.

As crianças de 6 a 9 anos são muito reacionárias. Tudo o 
que elas pedem é que lhes seja dada bem pouca liberdade. Educadores severos para conterem seus impulsos descontrolados é o que elas reclamam. É esta a fase áurea da formação do superego, instância prepotente e dominadora que, se não for muito vigiada, vigiará o sujeito pelo resto da vida, incapacitando-o frequentemente a buscar novos prazeres. Na adolescência há como que a busca de uma trégua do superego. Isso não significa que o jovem não internalizou esta instância psíquica. Ela esta lá, só que, agora, numa espécie de latência. Digamos que o adolescente percebe o seu cão de fila superegóico, farejando bem de perto seus impulsos sexuais. Mas ele agora sabe driblar o filão. Então já pode ir ao encontro do grande amor, já pode ir buscar o seu desejo. Esta é a idade em que a libido está solta, dentro e fora do sujeito, nele e no outro ao mesmo tempo(SARAIVA, 2006, p.37-38, apud LEÃO, 1990).

Saraiva (2006, p.37), a propósito disso, destaca que ignorar a responsabilidade penal juvenil ao adolescente produz a sensação equivocada de impunidade, aspecto que ainda mais contribui para o mito da impunidade do menor. Produz-se um sentimento contraditório sobre a adolescência; uma fase quase idolatrada pelo mundo adulto, que ao mesmo tempo a inveja a condena; consagrado na expressão tão comum do cotidiano adulto em face do jovem: "Ah,se eu tivesse a tua idade com a experiência que tenho hoje".

Ramidoff (2008, p.27-28), acerca do desenvolvimento humano, assevera o que se pretende demonstrar com a análise ou a avaliação que se possa fazer sobre o desenvolvimento de um jovem, particularmente, de um adolescente autor de uma ação conflitante com a lei, já não pode mais se limitar à dimensão comportamental, ou seja, à situação de risco pessoal e social em que se encontra, precisamente por estar inserido circunstancialmente num evento infracional, isto é, situacional, mas, acima de tudo, deve-se perceber o jovem em sua totalidade subjetiva. Embora, transcender à expectativa comportamental-situacional seja emancipar o jovem em sua dignidade huma- 
na. A totalidade subjetiva do jovem não se restringe aos limites normativos ou mesmo da racionalidade que se imponha sobre este ou aquele instituto jurídico-legal, mas, sobremodo, é reconhecer a sua condição humano-existencial.

\section{MENORIDADE PENAL: "CLÁUSULA PÉTREA"}

Para uma breve conceituação sobre a noção de cláusulas pétreas, pode-se entendê-las como limitações materiais ao poder de reforma da Constituição de um Estado. Em outras palavras, são dispositivos que não podem ter alteração, nem mesmo por meio de emenda, ainda que somente tendentes a abolir as normas constitucionais relativas às matérias por elas definidas. A existência de cláusulas pétreas ou limitações materiais implícitas é motivo de controvérsia na literatura jurídica. Tem-se que demandam interpretação estrita, pois constituem ressalvas ao instrumento normal de atualização da Constituição (as emendas constitucionais). As disposições constitucionais transitórias são modificáveis mediante emenda constitucional, não sendo admitidas cláusulas pétreas fora do texto constitucional.

Mendes e Branco (2012, p. 139) ensinam que as cláusulas pétreas, além de assegurarem a imutabilidade de certos valores e preservarem a identidade do projeto do constituinte originário, participam, elas próprias como tais, também da essência inalterável desse projeto. Eliminar a cláusula pétrea é enfraquecer os princípios básicos do projeto do constituinte originário garantidos por ela.

Nesse sentido, a cláusula pétrea não existe tão só para remediar situação de destruição da Constituição, mas tem a missão de inibir a mera tentativa de abolir o seu projeto básico, com a pretensão de evitar que a sedução de apelos próprios de certo momento político destrua um projeto duradouro (MENDES; BRANCO, 2012, p.140). 
As cláusulas pétreas inseridas na Constituição Federal da República Federativa do Brasil, de 1988, estão dispostas em seu art. $60, \S 4^{\circ}$, in verbis:

Art. 60. A Constituição poderá ser emendada mediante proposta.

[...]

Não será objeto de deliberação a proposta de emenda tendente a abolir:

I-a forma federativa de Estado;

II-o voto direto, secreto, universal e periódico;

III-a separação dos Poderes;

IV-os direitos e garantias individuais.

Em princípio, necessário esclarecer que o artigo supracitado, no qual as cláusulas pétreas estão inseridas, trata da forma como são elaboradas as propostas de modificação à Constituição, sendo que as quatro hipóteses listadas não podem ser modificadas, nem ao menos serem discutidas em qualquer proposta tendente à modificação constitucional. Isso se deve ao fato dos conceitos nelas contidos serem fundamentais na tradução das bases em que se estabelece a República Federativa do Brasil. Para modificá-las, só a partir da superação da atual Constituição (SANTIAGO, 2011).

Saldanha, faz a seguinte declaração a respeito da menoridade penal como cláusula pétrea:

Doutrinadores constitucionalistas, como José Afonso da Silva, defendem que a menoridade penal foi inserida no contexto das cláusulas pétreas, uma vez o art. $60, \mathrm{IV}, \S 4^{\circ}$ da $\mathrm{CF} / 88$ não esgota a matéria, devendo ser interpretado em conjunto com o art. $5^{\circ}$, onde há o elenco mais extensivo dos direitos e garantias do indivíduo, mas, à semelhança do art. 60, também não exaurem estes.

$\mathrm{O}$ que se quer dizer é que a questão da menoridade penal, em nosso entendimento, trata-se de cláusula pétrea, não sendo possível alteração mediante emendas à Constituição, 
portanto, discussão sem fertilidade.

Neste sentido, Maia (2013) esclarece que o art.228, por estabelecer um direito individual fundamental, relaciona-se à liberdade, notadamente, à liberdade do adolescente, uma vez que esse está ainda em formação. Em face de o Estado, não pode ser alterado por emenda constitucional que vise a restringir esse direito, pois este faz parte do regime especial dos direitos fundamentais, incidindo a limitação do art. 60, $\S$ $4^{\circ}$, IV, da Constituição Federal de 1988.

$\mathrm{O}$ art. 228 da Constituição Federal busca garantir a não imputação criminal, e o consequente cerceamento da liberdade da pessoa menor de 18 (dezoito) anos, que deverá receber uma proteção especial por parte do Estado, uma vez que o Poder Constituinte Originário entendeu que o adolescente menor de 18 (dezoito) anos ainda é um ser em desenvolvimento físico, mental, espiritual, emocional e social (MAIA, 2013).

Portanto, quando a Magna Carta de 1988, no caput do art. 228, afirma que as pessoas menores de 18 (dezoito) anos são penalmente inimputáveis, na verdade garante expressamente que toda pessoa menor de 18 (dezoito) anos terá um tratamento especial quando praticar atos contrários à lei penal (MAIA, 2013).

$\mathrm{Na}$ mesma esteira, Pereira (2005, p.18) defende que, do ponto de vista estritamente jurídico, a rigor a questão pode ser considerada superada pelo fato de que a proteção integral dos direitos da criança e do adolescente encontra guarida na Constituição Federal, notadamente nos arts. 227 e 228.

$\mathrm{O}$ direito a tratamento diferenciado dos menores que cometam atos tipificados como crimes ou contravenções penaispossui a mesma natureza dos direitos e garantias individuais arrolados no art. $5^{\circ}$ da Constituição e outros dispersos pelo texto constitucional. E, como tal, reveste-se do caráter de cláusula pétrea, não podendo por isso mesmo, ser objeto de emenda 
constitucional que vise à sua abolição, como se extrai da leitura do art. 60, $\S 4^{\circ}$, IV da Constituição Federal (PEREIRA, 2005, p.18).

Acrescenta Pereira (2005, p.18):

Não se pode, ainda, atribuir o aumento da criminalidade à "impunidade de criminosos" como afirmamos defensores da pretensão da redução da maioridade penal. Há fatores sociais e políticos a serem considerados na questão.

Não se justifica, ainda, a referida pretensão sob o argumento de que há impunidade, em vista da tutela do Estatuto da Criança e do Adolescente. As sanções previstas pelo Estatuto para as infrações são tão ou mais severas que as penas previstas para as mesmas condutas tipificadas como crimes no Código Penal. O que ocorre é a não-aplicação das medidas previstas pelo Estatuto, do mesmo modo como muitas penas previstas pelo Código Penal não são aplicadas em virtude de deficiências no funcionamento da Justiça Criminal ou na aplicação defeituosa da Lei de Execução Penal (PEREIRA, 2005, p.18).

Sobre o assunto Saraiva (2009, p. 90) afirmaque:

$\mathrm{O}$ art. 228, ao estabelecer a idade mínima para a imputabilidade penal, assegura a todos os cidadãos menores de dezoito anos uma posição jurídica subjetiva, qual seja, a condição de inimputável diante do sistema penal. E tal posição, por sua vez, gera uma posição jurídica objetiva: a de ter a condição de inimputável respeitada pelo Estado.

Os proponentes da ideia de redução da idade de imputabilidade penal, destituída de fundamentação apta a legitimá-la e construída no desconhecimento do sistema terciário de prevenção insculpido no Estatuto, fundado no Direito Penal Juvenil, desprezam a natureza de cláusula pétrea desta disposição constitucional (SARAIVA,2009, p. 90).

Opina Barbosa (2009) a respeito da redução da menoridade penal, independentemente das conclusões advindas dos inú- 
meros debates que questionam as vantagens ou desvantagens da redução da maioridade penal, essa discussão se torna absolutamente inócua diante da existência de óbices jurídicos intransponíveis, que proíbem a modificação do art. 228 da Constituição Federal.

$\mathrm{O}$ art. $60, \S 4^{\circ}$ da Constituição, responsável por trazer ao nosso ordenamento as chamadas cláusulas pétreas, proíbe a elaboração de proposta de emenda constitucional tendente a abolir direitos ou garantias fundamentais. Significa dizer: direitos e garantias fundamentais não podem ser retirados do texto constitucional (BARBOSA, 2009).

Segundo Barbosa (2009), a previsão de direitos e garantias fundamentais não se esgota no rol do art. $5^{\circ}$ da Constituição. Logo, o referido art. 228, ao fixar a idade inicial para responsabilização penal aos dezoito anos, acoberta, indiscutivelmente, o direito fundamental do adolescente, agasalhado por cláusula pétrea, de não submissão aos ditames do Direito Penal.

A propósito dos direitos e garantias fundamentais Maia (2013) comenta que

Os direitos e garantias fundamentais, pelo seu conteúdo e significado histórico, sobrepõem-se em importância aos demais direitos, pelo que formam o objeto de um regime especial, caracterizado por, dentre outros fatores, a aplicabilidade imediata e a impossibilidade de restrição, mesmo que por emenda constitucional.

$\mathrm{Na}$ realidade, para que possamos classificar um direito como individual, não devemos nos ater tão somente à sua topografia, mas, principalmente, às suas características intrínsecas.

As proteções especiais conferidas aos adolescentes não devem ser entendidas como incentivo à violência, decorrente da sensação de impunidade pelas infrações cometidas por menores de 18 anos, pois, certamente, o que se garante constitucionalmente é a liberdade desses jovens não ser tolhida da 
mesma maneira que seria de um maior de 18 anos. No entanto, eles não terão nenhuma reprimenda pelas infrações cometidas (MAIA, 2013).

No outro extremo, os defensores da ideia de que o art. 228 nãorepresenta uma cláusula pétrea, portanto a redução da maioridade penal torna-se possível mediante emenda constitucional. A respeito do tema, segue exposição de argumentos dos seguintes doutrinadores.

Acerca do art. 228 da Constituição Federal, apesar da inserção no texto de nossa Constituição Federal referente à maioridade penal, Rogério Greco (2013, p. 87) assevera que tal fato não impede, caso haja vontade política para tanto, de ser levada a efeito sua redução, uma vez que o mencionado artigo não se encontra entre aqueles considerados irreformáveis, uma vez que não se amolda ao rol das cláusulas pétreas listadas nos incisos I a IV do $\S 4^{\circ}$ do art.60 da Carta Magna.

A única implicação prática da previsão da inimputabilidade penal no texto da Constituição Federal, segundo posicionamento, é que, agora, somente por meio de um procedimento qualificado de emenda, a maioridade penal poderá ser reduzida, ficando impossibilitada tal redução via lei ordinária Rogério Greco (2013, p.87).

A propósito da redução ou mantença da idade de 18 anos como padrão para a responsabilização penal, Nucci (2008, p.217) leciona que:

a questão proposta envolve, naturalmente, dois aspectos, um deles subdividido: a) jurídico, que se decompõe em: a.1) constitucional; a.2) penal; b) político-criminal ou meramente político. Sob o prisma jurídico-constitucional desenvolve-se a seguinte polêmica: seria o art. 228 da Constituição Federal uma cláusula pétrea? Se afirmativa a resposta, nem mesmo por Emenda Constitucional se poderia alterar a responsabilidade penal no Brasil, reduzindo-a 
para qualquer patamar abaixo dos dezoito anos. Se negativa, havendo Emenda que suprima o referido art. 228, em seguida, poder-se-ia rever o art. 27 do Código Penal, fornecendo outros critérios para a apuração da idade ideal para a responsabilização do de fato criminoso. Posicionamo-nos pela tese que nega o caráter de cláusula pétrea ao art. 228 da Constituição Federal de 1988.

A respeito do art. 228 da Constituição Federal representar uma cláusula pétrea, $\operatorname{Lenza}(2011$, p. 260) expõeque:

[...] nostermos do art. 228 da $\mathrm{CF} / 88$, são penalmente inimputáveis os menores de 18 anos, sujeitos às normas da legislação especial.Muito se cogita a respeito da redução da maioridade penal, de 18 para 16 anos. Para tanto, o instrumento necessário seria uma emenda à Constituição e, portanto, manifestação do poder constituinte derivado reformador, limitado juridicamente.

Neste ponto, resta questionar se eventual Emenda Constitucional que reduzisse a maioridade penal, por exemplo, de 18 para 16 anos, violaria a cláusula pétrea do direito e garantia individual (art. 60, $§ 4^{\circ}$, IV)?

Segundo Lenza (2011, p. 260), embora parte da doutrina assim entenda, a posição é no sentido de ser perfeitamente possível à redução de 18 para 16 anos, uma vez que apenas não se admite a proposta de emenda constitucional (PEC) tendente a abolir direito e garantia individual. Isso não significa como já interpretou o STF, que a matéria não possa ser modificada.

Nesse sentido, acrescenta Lenza (2011, p. 260) que, reduzindo a maioridade penal de 18 para 16 anos, o direito à inimputabilidade, visto como garantia fundamental, não deixará de existir.

A sociedade evoluiu, e, atualmente, uma pessoa com 16 anos de idade tem total consciência de seus atos, tanto é que exerce os direitos de cidadania, podendo propor a ação popular e votar. Portanto, o autor entende que eventual Proposta de Emenda Constitucional que reduza a maioridade penal de 18 
para 16 anos é totalmente constitucional. O limite de 16 anos já está sendo utilizado e é fundamentado no parâmetro do exercício do direito de votar e à luz da razoabilidade e maturidade do ser humano (LENZA, 2011 p. 260).

Sobre o tema, Garcia (2011) posiciona-se utilizando os seguintes termos:

Poder-se-ia discorrer longamente sobre a posição topográfica do art. 228 da Constituição Federal de 1988, negando-lhe o caráter de direito individual e cláusula pétrea, pois o marco presuntivo de incapacidade criminal não está disposto no rol do art. $5^{\circ}$, não estando, pois, dentro do catalogo de direitos formalmente fundamentais. Caso fosse, neste sentido, a intenção e vontade do legislador constituinte originário, teria tido o cuidado de referi-lo nesta primeira parte do texto constitucional.

Consequentemente, pode-se considerar tal limite etário de 18 anos como indicador constitucional colocado pelo constituinte originário no sentido de referência para o legislador infraconstitucional, o que, portanto, possibilitaria a sua mudança por via reformadora derivada (GARCIA, 2011).

\section{CONCLUSÃO}

Pelo que restou aqui debatido, embora assustadora a sensação de insegurança da sociedade em geral, com o considerável aumento da repercussão sobre crimes envolvendo menores, como autores ou partícipes de atos infracionais, inegavelmente parece um grave equívoco acreditar que a redução da menoridade penal represente a solução para essa complexa problemática.

Cabe considerar o especial tratamento atribuído pela Constituição Federal de 1988 e, consequentemente, pelo Estatuto da Criança e do Adolescente ao respeito à peculiar condição de pessoa em desenvolvimento. Estudos psicológicos apontam que o ser humano nessa faixa etária não apresenta maturidade 
suficiente para determinar suas escolhas, tornando-se suscetível a influências externas, portanto para que não receba uma punição como se adulto fosse, aufere um tratamento diferenciado nessa fase da vida.

Por sua vez, aqueles que defendem a redução da maioridade penal ignoram o fato de que, uma vez inserido no falido sistema penitenciário brasileiro, sem possuir o necessário desenvolvimento físico e psíquico para tanto, o jovem não terá qualquer chance de recuperação e, certamente, voltará a delinquir. Ou seja, não consideram o fato de que o adolescente é um ser ainda em desenvolvimento e, portanto, ainda em formação. Então,em vez de transparecer a solução do problema, o recolhimento ao sistema penitenciário irá agravá-lo ainda mais, pois, aquele que ingressa numa penitenciária sai pior do que era quando entrou. Assim sendo, conduzir os adolescentes ao sistema prisional é contribuir para o aumento da criminalidade.

A redução da menoridade penal é um tema bastante controvertido. Debates que tratam das vantagens ou desvantagens neste sentido nos revelam a preponderância de argumentos contrários a tal modificação. A referida redução pode representar, inclusive, uma afronta tanto aos ditames constitucionais quanto a legislação especial, qual seja, o Estatuto da Criança e do Adolescente, no que concernem aos princípios da peculiar condição de pessoa em desenvolvimento e princípio da prioridade absoluta.

Por fim, há sólidos argumentos no sentido de considerar o art. 228 da Constituição Federal como cláusula pétrea. Embora não esteja explícito no art. $60 \S 4^{\circ}$, a idade penal pode ser lida como uma cláusula pétrea, ante a leitura do inciso seu IV, que descreve as garantias individuais fundamentais como tal, razão pela qual a menoridade penal configuraria uma garantia individual fundamental, portanto uma cláusula pétrea. 
Nesse sentido, conclui-se que eventual proposta de emenda constitucional que pretendesse alterar o texto do art. 228 da Constituição Federal poderia caracterizar não só uma violação à cláusula pétrea, mas também aos princípiospro hominee da proibição do retrocesso, o que admitiria, em tese, o próprio controle preventivo de constitucionalidade.

\section{REFERÊNCIAS}

BRASIL. Constituição (1988). Constituição da República Federativa do Brasil. Brasília, DF: Senado Federal, 1988.Disponível em: <http://www.planalto.gov.br/ccivil_03/ Constituicao/Constituicao.htm>. Acesso em: 15 maio 2014.

Lei n. 8.069, de 13 de julho de 1990. Estatuto da criança e do adolescente. Disponível em:<http://www.planalto.gov.br>. Acesso: 12 maio 2014.

BARBOSA, Danielle Rinaldi. Redução da Maioridade Penal: uma abordagem garantista.Disponível em: <http://ww3.lfg.com.br/public_html/article.php?story $=20091201180428721 \&$ mode $=$ print $>$. Acesso: 15 maio 2014 .

BRAZ, Mirele Alves. Os princípios orientadores da medida sócio-educativa e sua aplicação na execução. Disponível em: <http://jus.com.br/artigos/2282/os-principios-orientadores-da-medida-socio-educativa-e-sua-aplicacao-na-execucao\#ixzz31 ph5paGFhttp://jus.com.br/artigos/2282/os-principios-orientadores-da-medida-socio-educativa-e-sua-aplicacao-na-execucao\#ixzz31pgFU3xY>. Acesso: em 15 maio 2014.

GARCIA, Daniel Melo. A constitucionalidade da responsabilização criminal de crianças e adolescentes. Disponível em: <http://www.ambito-juridico.com.br/site/index. php?n_link=revista_artigos_leitura\&artigo_id=10622>. Acesso em: 13 abr. 2014.

GRECO, Rogério. Código penal: comentado. 7. ed.Niterói, Rio de Janeiro: Impetus, 2013.

ISHIDA, VálterKenji. Estatuto da criança e do adolescente: doutrina e jurisprudência. 13. ed. São Paulo: Atlas, 2011.

LENZA, Pedro. Direito constitucional esquematizado. 15. ed. rev. atual. e ampl. São Paulo : Saraiva, 2011.

MAIA, Daniel. Maioridade penal e a impossibilidade de sua redução no Direito brasileiro. Disponível em: <http://jus.com.br/artigos/20134/maioridade-penal-e-a-impossibilidade-de-sua-reducao-no-direito-brasileiro>. Acesso em: 22 maio2014.

MENDES, Gilmar Ferreira; BRANCO, Paulo Gustavo Gonet.Curso de direito constitucional. 7. ed. rev. e atual. São Paulo: Saraiva, 2012.

MORAIS, Bianca Mota de; RAMOS, Helane Vieira. A prática de ato infracional. In: MACIEL, Kátia Regina Ferreira Lobo de Andrade (Coord.). Curso de direito da criança e do adolescente: aspectos teóricos e práticos. 6. ed. São Paulo: Saraiva, 2013. 
NUCCI, Guilherme de Souza. Leis penais e processuais penais comentadas. 3. ed. rev. atual. e ampl. 2. tir.São Paulo: Revista dos Tribunais, 2008.

PEREIRA, Jozemir Loureiro. Maioridade penal:fatos e falácias. Revista Bonijuris Ano XVII - n. 502 - Set. 2005. Editor: Jornalista Arnoldo Anater DRT - 347/ 03/74 $-\mathrm{PR}$.

RAMIDOFF, Mário Luiz. Lição de direito da criança e do adolescente. Curitiba: Juruá, 2008.

SALDANHA, Ana Maria Pires. Menoridade penal em face as escolas sociológicas do crime.Disponível em: <http://sisnet.aduaneiras.com.br/lex/doutrinas/arquivos/face. pdf>. Acesso em: 13 maio 2014.

SANTIAGO, Emerson.Cláusulas pétreas da constituição de 1988.Disponível em: $<$ http://www.infoescola.com/direito/clausulas-petreas-da-constituicao-de-1988/>. Acesso em: 14 maio2014.

SARAIVA, João Batista Costa. Adolescente em conflito com a lei: da diferença à proteção integral: uma abordagem sobre a responsabilidade penal juvenil. 3. ed. rev. ampl. Porto Alegre: Livraria do Advogado, 2009.

SARAIVA, João Batista Costa. Compêndio de direito penal juvenil: adolescente e ato infracional. 3. ed. rev. ampl. Porto Alegre: Livraria do Advogado, 2006.

VILAS-BÔAS, Renata Malta. A doutrina da proteção integral e os princípios norteadores do direito da infância e juventude. Disponível em: $<$ http://www.ambito-juridico. com.br/site/?n_link=revista_artigos_leitura\&artigo_id $=10588 \&$ revista_caderno $=12>$. Acesso em: 13 abr. 2014.

Artigo recebido em 30/05/2016

Artigo aprovado em 05/07/2016 